\title{
Antibiotic-loaded bone cement combined with vacuum sealing drainage to treat deep sternal wound infection following cardiac surgery: the first case report
}

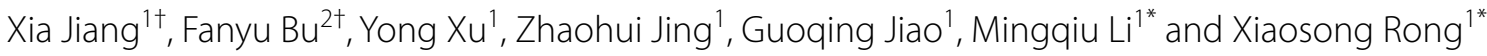

\begin{abstract}
Background: Deep sternal wound infection (DSWI) is a rare but serious complication after median sternotomy, and treatment success depends mainly on surgical experience. Here we first present a case of a patient successfully treated for antibiotic-loaded bone cement (ALBC) combined with vacuum sealing drainage (VSD) of DSWI.

Case presentation: This case report presented a patient who underwent open heart surgery, and suffered postoperatively from a DSWI associated with enterococcus cloacae. Focus debridement combined with ALBC filling and VSD was conducted in stage I. Appropriate antibiotics were started according to sensitivity to be continued for 2 weeks until the inflammatory markers decreased to normal. One month after the surgery, patient's wound was almost healed and was discharged from hospital with a drainage tube. Two months after the stage I surgery procedure, the major step was removing the previous ALBC, and extensive debridement in stage II. The patient fully recovered without further surgical treatment.
\end{abstract}

Conclusions: The results of this case suggest that ALBC combined with VSD may be a viable and safe option for deep sternal wound reconstruction.

Keywords: Antibiotic-loaded bone cement, Vacuum sealing drainage, Deep sternal wound infection

\section{Background}

Deep sternal wound infection (DSWI) is a rare but potentially devastating complication of median sternotomy performed in cardiac surgery. The incidence of this complication ranges between 1 and $3 \%[1,2]$ and on average mortality of $10-47 \%[3,4]$. It is difficult to treat when compared to skin and subcutaneous tissue infections. We herein report a successful treatment of DSWI after open heart surgery with ALBC and VSD.

\footnotetext{
*Correspondence: LMQ.2109@163.com; rxswx@163.com

${ }^{+} X i a$ Jiang and Fanyu Bu have contributed equally to this work

1 Department of Cardiovascular Surgery, Wuxi People's Hospital/Wuxi Affiliated Hospital of Nanjing Medical University, Wuxi 214203, China

Full list of author information is available at the end of the article
}

\section{Case presentation}

Here we report the case of a 53-year old male patient, who underwent mitral valve replacement and coronary artery bypass surgery (LIMA to LADA) on April 16, 2019. He was a known case of diabetes and chronic obstructive pulmonary disease (COPD). Five weeks after surgery, the patient was referred to our center with a 1-week history of abundant discharge accompanied by fever $\left(39.5{ }^{\circ} \mathrm{C}\right)$, painful sternal instability, and shortness of breath. He had a purulent wound in the upper part of his sternotomy incision, with a fistula approximately $4 \mathrm{~cm}$ long (Fig. 1a). A computed tomography (CT) scan of the thorax conducted in response showed sternal non-union up to $7 \mathrm{~mm}$ wide (Fig. 1b). Inflammatory markers were significant with a white blood cell count original author(s) and the source, provide a link to the Creative Commons licence, and indicate if changes were made. The images or other third party material in this article are included in the article's Creative Commons licence, unless indicated otherwise in a credit line to the material. If material is not included in the article's Creative Commons licence and your intended use is not permitted by statutory regulation or exceeds the permitted use, you will need to obtain permission directly from the copyright holder. To view a copy of this licence, visit http://creativecommons.org/licenses/by/4.0/. The Creative Commons Public Domain Dedication waiver (http://creativeco mmons.org/publicdomain/zero/1.0/) applies to the data made available in this article, unless otherwise stated in a credit line to the data. 


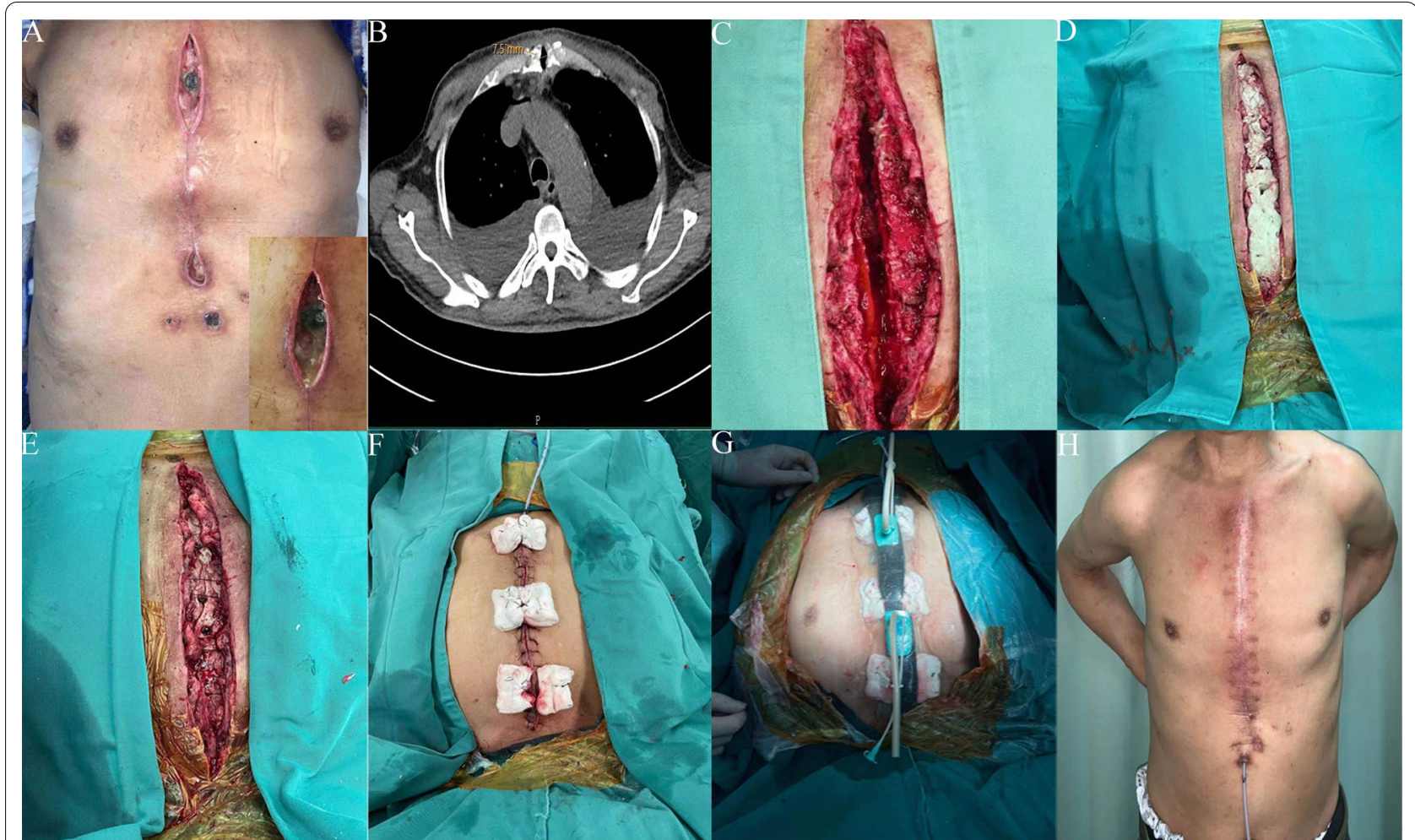

Fig. 1 I-stage surgical procedure of the DSWI. a Post-sternotomy wound infection; b Chest CT revealed sternal dehiscence and non-unionc; cThe wound after debridement; $\mathbf{d}$ ALBC was inseted on the sternal defect; $\mathbf{e}$ Mobilization of pectoralis major muscle flap and intermittent sutures; $\mathbf{f}$ Deep sternal wound infection-associated defect after reconstruction and skin suture; $\mathbf{g}$ VSD coverage; $\mathbf{h}$ 4th postoperative week

of $19.5 \times 10^{9} / \mathrm{L}$ and an erythrocyte sedimentation rate (ESR) of $77 \mathrm{~mm} / \mathrm{H}$. A C-reactive protein (CRP) level was $105.9 \mathrm{mg} / \mathrm{L}$. Serum albumin and hemoglobin were $28 \mathrm{~g} / \mathrm{L}$ and $85 \mathrm{~g} / \mathrm{L}$, respectively. The wound culture examination revealed vancomycin-sensitive enterococcus cloacae. DSWI with sternal dehiscence was the diagnosis. An operation was scheduled immediately because of severe infection symptoms on May 28, 2019. General anesthesia was administered to this patient prior to surgery. The surgical technique was divided in two stages. Stage I: (1) aggressive debridement was performed on this patient. All abnormally proliferated granulation tissue and residual foreign bodies were removed. Then, the wound was rinsed repeatedly with hydrogen peroxide, iodophor, and normal saline (Fig. 1c). (2) Antibiotic impregnated cement (PALACOS MV® $+\mathrm{G}$ bone cement, Heraeus, Heraeus Medical $\mathrm{GmbH}$, Wehrheim, Germany) was prepared by combining a $40 \mathrm{~g}$ bag of cement with $2 \mathrm{~g}$ of vancomycin. The sternal defect was filled with an appropriate amount of ALBC, which provided a reliable bone coverage (Fig. 1d). Also, the holes were made on the surface of ALBC for drainage. (3) Next, bilateral pectoralis major muscle flaps and subcutaneous tissue were raised off, from the chest wall to adistance of about $4 \mathrm{~cm}$ from incision margin (Fig. 1e). Furthermore, the drainage tube was placed between ALBC and the subcutaneous layer. And then, the skin was relaxedly sutured without significant tension (Fig. 1f). Finally, the skin around the wound was cleaned with $75 \%$ alcohol and a semipermeable membrane was used to seal the wound and the VSD (Wu han VSD Medical Science \& Technology Co., Ltd. Vacuum Sealing Drainage Dressing VSD-D-2-15*10 cm) dressing (Fig. $1 \mathrm{~g}$ ), the negative pressure is $-75 \mathrm{mmHg}$ to $-100 \mathrm{mmHg}$. The VSD was not changed during the treatment, and it was removed after intermittent use for 1 week. The drainage-fluid culture (tested twice), ESR, and CRP were normal after 10 days of intravenous vancomycin antibiotics therapy. The thoracic cage was stable and he was symptom-free (Fig. 1h).

Two months after the stage I surgery procedure, our final step was removing the previous ALBC (Fig. 2a), and extensive debridement in stage II. The second re-exploration revealed a clean, red, granulating wound bed was achieved (Fig. 2b). Subsequently, the bilateral pectoralis major muscle flap were mobilized from the thorax wall again (Fig. 2c, d). The subcutaneous tissue and bilateral pectoralis major muscle flap were intermittently sutured to cover sternum defect by methods of relieving tension 


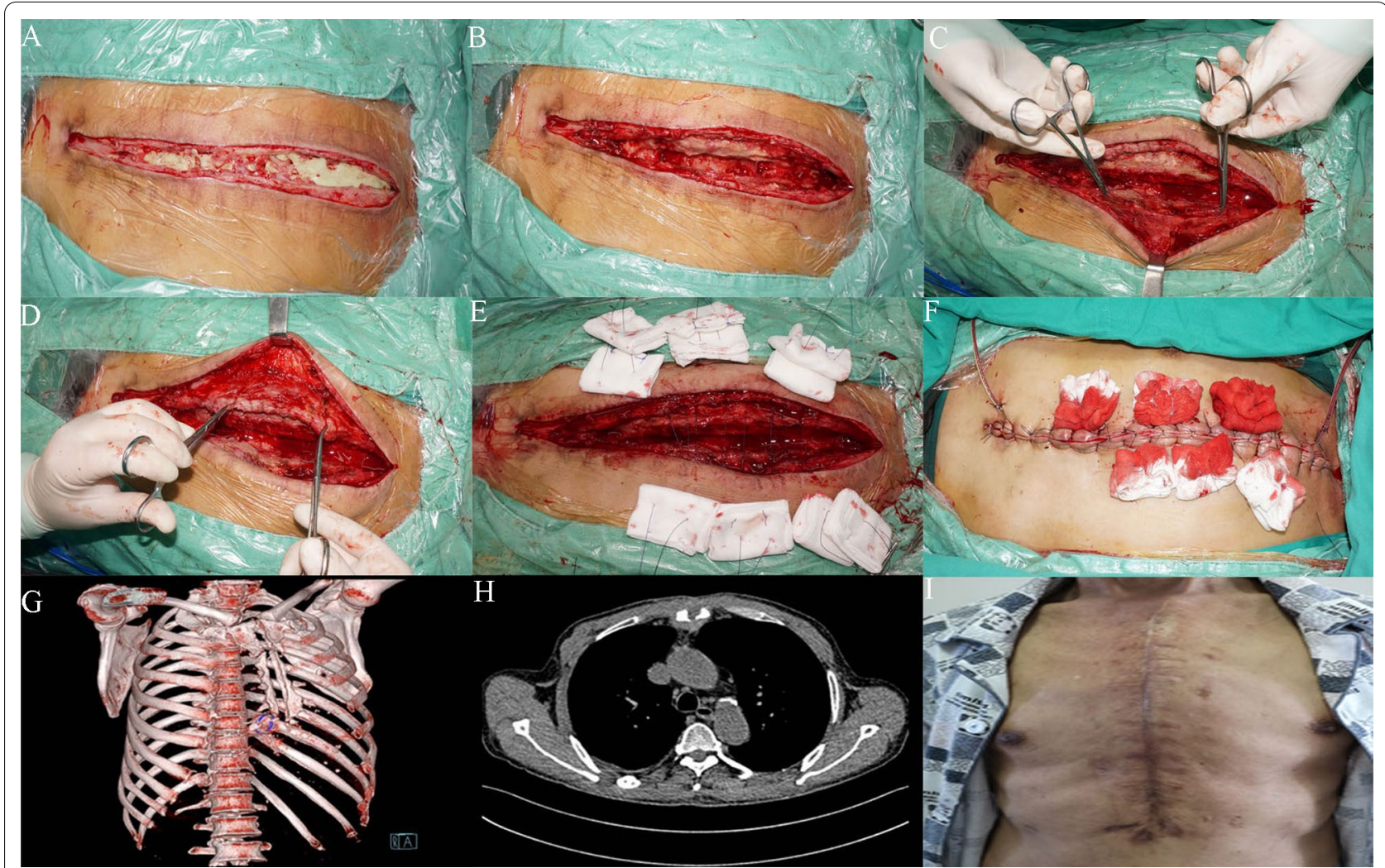

Fig. 2 II-stage surgical procedure of the DSWI. a ALBC covering the surface of sternal; $\mathbf{b}$ The wound after removing the retained ALBC and complete debridement; c Mobilization of left pectoralis major muscle flap; $\mathbf{d}$ Mobilization of right pectoralis major muscle flap; $\mathbf{e}$ The subcutaneous tissue and pectoralis major muscle flap were intermittently sutured by methods of relieving tension and no residual foreign bodies; $\mathbf{f}$ Drain tubes were placed: one under the muscle flap and the other under the subcutaneous layer; $\mathbf{g}$ Three-dimensional rib reconstruction revealed sternal dehiscence; $\mathbf{h}$ CT image of 3 months after final surgical reconstruction; $\mathbf{i}$ Healed sternal wound at the 3-month postoperative visit

and no residual foreign bodies (Fig. 2e). Furthermore, two drain tubes were placed: one under the muscle flap and the other under the subcutaneous layer (Fig. 2f). Sutures were removed 14 days after the operation and this patient was discharged in good local and general condition on August 17, 2019, 20 days after the stage II surgery. Drainage tubes were removed when output was less than $5 \mathrm{ml} /$ day for 3 days. Three months postoperatively, the skin healed nicely (Fig. 2I), and three-dimensional rib reconstruction revealed sternal dehiscence as before (Fig. 2g). A final CT scan documented scar tissue covering the mediastinum (Fig. 2h). More than 1 years after this surgery, the patient did not relapse.

\section{Discussion and conclusions}

One of the life-threatening complications that occurs in patients following cardiovascular surgery through median sternotomy is DSWI. As defined by the Centers for Disease Control and Prevention [5], DSWI diagnosis requires at least one of the following criteria: (I) an organism is isolated from culture of mediastinal tissue or fluid; (II) evidence of mediastinitis seen during surgery; (III) one of the following conditions: chest pain, sternal instability, or fever $\left(>38^{\circ} \mathrm{C}\right)$ in combination with either purulent discharge from the mediastinum or isolation of an organism from culture of blood or mediastinal drainage. This case was diagnosed with DSWI by an attending physician and an chronic wound control physician during his hospital stay period based on the definition of DSWI. Many authors have investigated the aetiology of DSWI in the past decades. Patient-related risk factors include age, diabetes, renal failure, smoking, obesity, and COPD $[6,7]$. Risk factors during surgery are internal mammary artery use (decreased sternal bone blood flow), increasing number of grafts, re-exploration for bleeding, blood product usage [8-10]. Current treatment comprises antibiotics, debridement, VSD wound therapy and sometimes transposition of muscle or omental flaps to fill the anterior mediastinal dead space. Antibiotic-loaded cement were first introduced by Klemm for the treatment of osteomyelitis [11]. It can deliver a high concentration of drug locally even in an avascular area and provide 
superior mechanical support [12], which has been widely applied to control bone infections in open fractures [13], osteomyelitis [14], and prosthetic joint infections [15]. Compared with reports on wounds in other parts of the body, there are relatively few published reports on the use of the ALBC for DSWI. VSD is an efficient drainage system and its efficiency embodies its comprehensive drainage and thorough drainage under high vacuum. It promptly and thoroughly leads seepage, pus and necrotic tissues from the drainage area out of the body to cause "zero accumulation" in the drainage area [16]. But for patients undergoing bypass surgery, the negative pressure of VSD may damage the bypass vessels. Now, VSD combined with flap metastasis has become an effective treatment for DSWI. Pitfalls of the muscle flap technique are mostly hematoma, arm strength loss, chest wall instability, infection, and pulmonary function impairment [17]. Aiming at the infection and sternal instability problems of DSWI, we apply the ALBC to our sternal reconstruction system. However, it is not clear whether the ALBC should be removed. For this patient, he had no complication. Some authors raised concerns regarding the release of cytotoxic monomers from cement including local inhibition of bone perfusion and remodeling, as well as an increased production of tumor necrosis factor possibly leading to a systemically increased bone resorption [18]. There is some unknown long-term result in the sternum that fixed with bone cement. Therefore, we decided to remove the bone cement after a period of time.

The main experience of our technique is as follows. (1) Extensive debridement followed by dead space management and adequate antibiotics administration is crucial for this patient. (2) ALBC can be adjusted to fill the wound cavity according to the size of the wound defect, leaving no dead space. After bone cement hardened, it fixed the thorax and eliminated the residual cavity. It could also be removed without difficulty if needed. (3) The antibiotics that can be used in bone cement preparation are various, in accordance with the particular sensitivity sought, providing superior mechanical support and high levels of local antibiotics. (4) VSD device is advantageous by providing continuous negative pressure to force drainage, also for eliminating residual cavity, and enhancing adhesion of subcutaneous tissue. VSD was not changed during the whole treatment, and it was removed after intermittent use for 1 week in Stage I. (5) No residual suture technique was used to fix the muscle flap, which reduced the occurrence of foreign-body infections.

\section{Conclusion}

Although this strategy should be applied to a larger number of patients, the findings described here indicate that ALBC combined with VSD is a possible treatment option for DSWI after cardiovascular surgery, especially for those patients who are not suitable for muscle flap transfer. Future prospective, randomized controlled trials will provide a more rigorous assessment of its efficacy.

\section{Abbreviations \\ LIMA: Left internal mammary artery; LADA: Left anterior descending artery; ALBC: Antibiotic-loaded bone cement; VSD: Vacuum sealing drainage; CT: Computed tomography.}

\section{Acknowledgements}

Not applicable.

\section{Authors' contributions}

$\mathrm{XJ}$ and $\mathrm{FB}$ drafted and edited this manuscript, assisted in the surgery, and analysed the patient data. YX, ZJ and GJ were involved in the treatment and care as the patient's main doctors. ML and XR performed the surgery, edited this manuscript, and analysed the patient data. All authors read and approved the final manuscript.

\section{Funding}

Not applicable.

\section{Availability of data and materials}

As this paper is a case report, all data generated or analysed are included in this article.

\section{Declarations}

\section{Ethics approval and consent to participate}

This study was approved by the Ethics Committee of Wuxi People's Hospital/ Wuxi Affiliated Hospital of Nanjing Medical University, Wuxi, China. Informed consent was obtained from the patient for participation in the study.

\section{Consent for publication}

We have obtained written consent from the patient to publish the medical data in this case report.

\section{Competing interests}

The authors declare that they have no competing interests.

\section{Author details}

${ }^{1}$ Department of Cardiovascular Surgery, Wuxi People's Hospital/Wuxi Affiliated Hospital of Nanjing Medical University, Wuxi 214203, China. ${ }^{2}$ Department of Chronic Wound, Wuxi Ninth People's Hospital Affiliated to Soochow University, Wuxi 214062, China.

Received: 4 July 2021 Accepted: 25 September 2021

Published online: 10 October 2021

\section{References}

1. Clarkson JH, Probst F, Niranjan NS, Meuli C, Vogt P, Lidman D, Andersson LC. Our experience using the vertical rectus abdominis muscle flap for reconstruction in 12 patients with dehiscence of a median sternotomy wound and mediastinitis. Scand J Plast Reconstr Surg Hand Surg. 2003:37(5):266-71.

2. Morisaki A, Hosono M, Sasaki Y, Hirai H, Sakaguchi M, Nakahira A, Seo H, Suehiro S, Shibata T. Evaluation of risk factors for hospital mortality and current treatment for poststernotomy mediastinitis. Gen Thorac Cardiovasc Surg. 2011;59(4):261-7.

3. Gummert JF, Barten MJ, Hans C, Kluge M, Doll N, Walther T, Hentschel B, Schmitt DV, Mohr FW, Diegeler A. Mediastinitis and cardiac surgery-an updated risk factor analysis in 10,373 consecutive adult patients. Thorac Cardiovasc Surg. 2002;50(2):87-91. 
4. Losanoff JE, Richman BW, Jones JW. Disruption and infection of median sternotomy: a comprehensive review. Eur J Cardiothorac Surg. 2002:21(5):831-9.

5. Garner JS, Jarvis WR, Emori TG, Horan TC, Hughes JM. CDC definitions for nosocomial infections, 1988. Am J Infect Control. 1988;16(3):128-40.

6. Lepelletier D, Bourigault C, Roussel JC, Lasserre C, Leclere B, Corvec S, Pattier S, Lepoivre T, Baron O, Despins P. Epidemiology and prevention of surgical site infections after cardiac surgery. Med Mal Infect. 2013:43(10):403-9.

7. Leung Wai Sang S, Chaturvedi R, Alam A, Samoukovic G, de Varennes B, Lachapelle K. Preoperative hospital length of stay as a modifiable risk factor for mediastinitis after cardiac surgery. J Cardiothorac Surg. 2013;8:45.

8. Lu J. Risk factors for sternal wound infection and mid-term survival following coronary artery bypass surgery. Eur J Cardio-Thorac Surg. 2003;23(6):943-9.

9. Andreas $M$, Zeitlinger M, Hoeferl M, Jaeger W, Zimpfer D, Hiesmayr JM, Laufer $G$, Hutschala D. Internal mammary artery harvesting influences antibiotic penetration into presternal tissue. Ann Thorac Surg. 2013;95(4):1323-9 (discussion 1329-30).

10. Crabtree TD, Codd JE, Fraser VJ, Bailey MS, Olsen MA, Damiano RJ Jr. Multivariate analysis of risk factors for deep and superficial sternal infection after coronary artery bypass grafting at a tertiary care medical center. Semin Thorac Cardiovasc Surg. 2004;16(1):53-61.

11. Klemm KW. Antibiotic bead chains. Clin Orthop Relat Res. 1993;295:63-76.

12. Letchmanan K, Shen SC, Ng WK, Kingshuk P, Shi Z, Wang W, Tan $\mathrm{RBH}$. Mechanical properties and antibiotic release characteristics of poly(methyl methacrylate)-based bone cement formulated with mesoporous silica nanoparticles. J Mech Behav Biomed Mater. 2017:72:163-70.

13. Carver DC, Kuehn SB, Weinlein JC. Role of systemic and local antibiotics in the treatment of open fractures. Orthop Clin N Am. 2017:48(2):137-53.

14. Wentao Z, Lei G, Liu Y, Wang W, Song T, Fan J. Approach to osteomyelitis treatment with antibiotic loaded pmma. Microb Pathog. 2017:102:42-4.

15. Chang Y, Tai CL, Hsieh PH, Ueng SW. Gentamicin in bone cement: a potentially more effective prophylactic measure of infectionin joint arthroplasty. Bone Joint Res. 2013;2(10):220-6.

16. Liu X, Liang J, Zao J, Quan L, Jia X, Li M, Tao K. Vacuum sealing drainage treatment combined with antibiotic-impregnated bone cement for treatment of soft tissue defects and infection. Med Sci Monit. 2016;22:1959-65.

17. Eriksson J, Huljebrant I, Nettelblad H, Svedjeholm R. Functional impairment after treatment with pectoral muscle flaps because of deep sternal wound infection. Scand Cardiovasc J. 2011;45(3):174-80.

18. Grafe IA, Baier M, Noldge G, Weiss C, Da Fonseca K, Hillmeier J, Libicher M, Rudofsky G, Metzner C, Nawroth P, Meeder PJ, Kasperk C. Calciumphosphate and polymethylmethacrylate cement in long-term outcome after kyphoplasty of painful osteoporotic vertebral fractures. Spine (Phila Pa 1976). 2008;33(11):1284-90.

\section{Publisher's Note}

Springer Nature remains neutral with regard to jurisdictional claims in published maps and institutional affiliations.
Ready to submit your research? Choose BMC and benefit from:

- fast, convenient online submission

- thorough peer review by experienced researchers in your field

- rapid publication on acceptance

- support for research data, including large and complex data types

- gold Open Access which fosters wider collaboration and increased citations

- maximum visibility for your research: over 100M website views per year

At BMC, research is always in progress.

Learn more biomedcentral.com/submissions 